\title{
CITIES FUTURES. A CRITICAL ASSESSMENT OF HOW FUTURE STUDIES ARE APPLIED TO CITIES
}

\section{José Miguel Fernández-Güell \& Javier González-López}

\author{
Organization: Universidad Politécnica de Madrid \\ Address: Departamento de Urbanística y Ordenación del Territorio -- Escuela Técnica Superior de Arquitectura - Avenida \\ Juan de Herrera, 4 - 28040 Madrid - Spain \\ E-mail: josemiguel.fernandez@upm.es
}

\begin{abstract}
In the past, urban planners have been quite reluctant to incorporate foresight methods in their professional practice, despite the benefits that they might have gained from using futures studies. Nevertheless, recent initiatives have been taken to bring foresight into the urban realm with differing outcomes: some have attained public notoriety, others have hardly benefitted from public exposure.

This paper tries to assess recent foresight exercises applied to cities by evaluating three major issues: (1) have foresight practitioners understood cities complexity?; (2) have urban planners employed adequate tools to generate plausible future visions?; and (3) are city policy makers using foresight studies to limit urban uncertainty? To answer these questions, a selected number of foresight examples were classified in distinctive categories and a set of assessment criteria was established.

Five futures studies taxonomies were distinguished. First, intergovernmental bodies have undertaken foresight exercises, which foresee the evolution of cities at a global o regional level. Second, the cities themselves have carried out foresight initiatives carried out, which are mostly linked to strategic planning processes. Third, some universities have developed visions of how cities may evolve in the future. Fourth, technology oriented corporations have explored how Smart Cities may resolve some key challenges faced by contemporary cities. Finally, architects and spatial planners have traditionally expressed on visual and narrative terms how cities should be designed and planned for the coming generations.

Obviously, such an array of heterogeneous approaches provides very different outcomes in terms of content and city impact. For undertaking an objective assessment, three criteria groups were established to evaluate different foresight approaches to cities: (a) how urban complexity was understood and interpreted by future visions; (b) what type of forward-looking activities were used to envision the future; and (c) what kind of direct and indirect impacts were generated by the foresight approach.

Those criteria were used to assess 20 case studies which either have international relevance or which constitute good illustrative examples of the five taxonomies mentioned before. Mostly secondary documented sources were used to validate cases' assessment. When public information was not considered sufficiently reliable, short electronic surveys were used to complete assessments.

Preliminary research outcomes show growing doubts about the appropriateness of the foresight tools employed in cities and about the competency of foresight practitioners in understanding the complex and dynamic nature of contemporary cities. Furthermore, policy makers do not seem to grasp the potential of foresight to formulate urban strategies. In brief, a critical assessment of these initiatives may provide some clues for developing new and more creative ways for envisioning futures in cities.
\end{abstract}

NOTE: This paper is based on partial results of a research project undertaken by the authors at the Urban and Regional Planning Department, Universidad Politécnica de Madrid

Keywords: Territorial foresight, urban planning, city futures, evaluation 


\section{Introduction}

Though foresight tools have been widely applied in numerous fields of knowledge during the last two decades, there are fewer well-known examples applied to the city realm. As stated in the literature (Isserman, 1985; Wachs, 2001), urban planners have been quite reluctant to incorporate foresight methods in their professional practice, despite the benefits that they may gain from using futures studies.

Among other reasons, in the last few decades urban planners had a hard time undertaking forecasts, since structural changes were making traditional paradigms obsolete. Confronted with this situation, most urban planners recognised their impotence for drawing reliable predictions, and turned toward short-term contingency planning as a way to navigate in a very uncertain context (Fernández Güell \& Redondo, 2012).

On the other hand, the high complexity of contemporary cities seems to have deterred foresight practitioners from drafting plausible city visions. In fact, most planners feel overcome by the multiplicity and multidimensional nature of urban problems. Cities are particularly complex systems because they present non-linear dynamics, they are made up of very diverse elements adaptable to changes, and they can transform themselves in very unpredictable ways (Fernández Güell, 2006).

Despite these obstacles, recent initiatives have brought foresight into the urban realm with differing outcomes: some have attained public notoriety, others have hardly benefitted from public exposure. Given these circumstances, this paper explores whether cities complexity has been understood in foreseeing the future of the city; whether adequate foresight approaches have been employed to generate plausible future visions; and whether foresight exercises have had a significant impact on the city.

Foresight impact has been recently a topic of much discussion in the specialised literature (Johnston, 2012; Calof et al., 2012); however, not much attention has been paid to assessing forward looking activities undertaken at cities. Though some efforts have been made to inventory urban foresight initiatives (Kubeczko et al., 2011), challenges remain for establishing a valid evaluation procedure. The heterogeneity of geographic scales and methodological approaches employed when visioning the future of cities complicates a cross-comparison study. In this respect, this paper makes a contribution to improve evaluation procedures.

\section{Assessment criteria}

For undertaking an objective assessment of city foresight initiatives, three criteria groups were established so as to answer the three major questions pursued by the study. A brief description of assessment criteria follows.

A) City complexity conceptualization. The first group of criteria assesses how initiatives about the future of the city understood and interpreted the complexity of urban systems. Three parameters were considered:

A1) Functional complexity. It derives from the large number and variety of operational processes, local stakeholders and relationships that take place within urban systems. Assessment is high when an initiative applies a multi-sectoral approach to the city, analyses internal relationships and undertakes an environmental scan.

A2) Territorial complexity. It refers to the functional relations among the city and the territorial network in which it operates. The territorial scale can be metropolitan, regional 
or even global. Assessment is high when an initiative considers functional relationships between the city and supra urban scales.

A3) Contextual complexity. It is defined by all those elements exogenous to the urban system, but which exercise a significant impact on it. Urban context is usually affected by socioeconomic transformations, technological innovations and environmental changes. Assessment is high when an initiative analyses explicitly external forces.

B) Methodological approach. The second group of criteria assess the methodological appropriateness of the forward-looking activity used to envision the future of the city. Three parameters were considered:

B1) Foresight quality. Technical quality of foresight initiatives can be determined by its methodological rigor and its adaptation to the urban realm (Fernández Güell, 2011). A foresight exercise will be helpful to an urban planner if it is supported by a sound analysis, it provides articulated visions or scenarios, and it anticipates implications of future visions. Assessment is high when the above mentioned requirements are satisfied.

B2) Stakeholders involvement. Participation of major urban stakeholders constitutes a key prerequisite for a foresight exercise. Given the ample heterogeneity of urban stakeholders, a segmented and structured participation process would be desirable. Assessment is high when the initiative has involved a wide range of urban stakeholders that represent diverse city interests and when participation has been well structured.

B3) Action oriented approach. Beyond conventional analysis and future visions, this approach is based on a strategic will to shape the future of the city through specific actions. Assessment is high when, besides strategic guidelines, the initiative includes operational roadmaps.

C) Study impact. The third group of criteria assess what kind of direct and indirect impacts were generated by the foresight approach. In other words, some foresight initiatives will influence decision making and others will not. Two parameters were considered:

C1) Direct impact. It shows if foresight exercises were translated in concrete urban policies or physical projects. Assessment is high when the objectives pursued by the initiative were achieved.

C2) Indirect impact. It measures if foresight initiatives have had impact not only in the urban spatial realm, but in other areas (economy, social), in other places (national or international) or in a wide spectrum of citizens. Assessment is high when initiative's impact is evident on several of areas.

\section{Assessment of case studies}

Twenty case studies were selected, which either have international relevance or are representative examples of recent foresight exercises. Those cases constitute a sample of how the future of the city is perceived by different groups of professionals. Mostly secondary documented sources were used to assess the cases. Google searches were carried out to assess specifically level of impact. When public information was not considered sufficiently reliable, short electronic surveys were used to complete assessments. The selected cases were grouped in five major taxonomies.

1. European Union Initiatives. Increasingly, intergovernmental bodies, such as the European Commission, try to foresee the future evolution of cities at a global or regional level. Specifically, 
the European Commission is interested in the role played by cities in promoting economic competitiveness, territorial cohesion and technological innovation. In this respect, urban studies undertaken by the Commission are beginning to incorporate foresight as part of their analysis. Four initiatives were assessed:

1.1. European Initiative on Smart Cities and Communities (EC, 2012; SCC-EIP, 2013). It establishes a guiding policy for promoting smart cities within the 2020 Horizon Plan. Urban complexity is contemplated through interactions between the three priority areas: energy, transport and ICTs. This initiative promotes stakeholders' involvement and it follows a clear road map. No foresight tools have been explicitly used, but they are welcome in bidding proposals. Impact is high because of abundant funds to finance real projects.

1.2. ET2050 Territorial Scenarios and Visions for Europe (ESPON, 2013). Its purpose is to formulate a plausible European territorial vision for 2050. This initiative focuses mainly on territorial complexity. It develops three alternative scenarios based on qualitative and quantitative approaches. The scenarios were drafted by experts in spatial planning without stakeholders' involvement, which supposedly will take place in future work stages. So far, impact has been restricted to the academic realm.

1.3. Joint Programming Initiative - Urban Europe (Austrian Ministry et al., 2010). This initiative aims at developing innovative approaches to address urban challenges, such as resilience, efficiency and quality of life. JPI Urban Europe has specific modules dedicated to understand urban systems, to assess future trends and to develop scenarios with relevant stakeholders. Impact is high because of large resources dedicated to finance real projects.

1.4. Cities of Tomorrow Report (EC, 2011). It analyses major change drivers and its future impacts on European cities. The study takes into consideration several urban dimensions and its functional interrelations. It was drafted by 50 experts and was mainly based on trend analysis. The Report has been widely distributed among academicians and policy makers.

2. Local Initiatives. There are foresight initiatives carried out by the cities themselves. These initiatives are mostly linked to strategic planning processes in order to support the decisionmaking process. Four initiatives were assessed:

2.1. Barcelona Vision 2020 (APEMB, 2010). It uses foresight analyses, such as trend analysis and visioning, to support the strategic vision of the city. Urban analysis is mostly focused on economic related issues, paying lesser attention to other urban dimensions. Local and regional stakeholders were involved in a Foresight Committee. The study's impact may be limited to local and regional stakeholders.

2.2. Donostia Strategy 2020 (PEDSS, 2011). As part of the Donostia Strategic Plan, alternative scenarios were developed to envision the Basque city in the 2020 horizon. The city was analyzed from multiple perspectives, but without applying a systemic approach. Scenarios were discussed and validated through a Delphi-SMIC survey carried out among a wide sample of local stakeholders. Results from the foresight exercise nurtured the strategies formulation process as well as the action plan.

2.3. Burgos Scenarios 2016 (APEB, 2009). This study was undertaken as part of the revision process of the Strategic Plan for the city of Burgos, Spain. Multiple urban dimensions are considered, though there is a weak link with spatial aspects. Four scenarios envision alternative paths to future development. More than 40 local and regional stakeholders were involved along the foresight process. No clear direct impacts are perceived on the city. 
2.4.Structural Vision Amsterdam 2040 (Lauwers et al., 2011). Its objective was to establish the city's aspirations toward 2040. Its major thematic areas were spatial planning, economic development and environmental sustainability. A visioning exercise was undertaken, supported by a wide bottom-up participation process. Impact should be high since the initiative was leaded by the city's physical planning department (DRO).

3. Academic Initiatives. Though not so much involved in foresight studies as governmental bodies, some universities have started their own lines of research on how cities may evolve in the future. Four initiatives were assessed:

3.1. London 2062 (Bell \& Paskins, 2013). This initiative was carried out by the University College of London to gather evidence about the forces that shape London and to envision what the city might be five decades from now. It deals with multiple urban dimensions by focusing on three issues: resilience, wellbeing and sustainability. This process involved experts from academia, government, professions, citizens and media through workshops. Future visions were produced by experts, but without the support of a conventional foresight method. Impact may be noticeable on London's stakeholders.

3.2. SUME (Schremmer et al., 2011). The FP7-funded project Sustainable Urban Metabolism for Europe (SUME) focuses on how future urban systems can be designed to be consistently less resource consuming than present. Interactions between society and urban environment are analyzed. Two long-term development scenarios are drawn for a selected group of cities in the 2050 horizon. Urban stakeholders were adequately segmented in the study. Impact may be significant among European policy makers since urban metabolism is attracting increasing attention.

3.3. Retrofit 2050 (Eames et al., 2013). It is a research project funded by the British EPSRC Sustainable Urban Environments Programme, which aims to support city-regional scale retrofitting in order to manage socio-technical transition in the built environment. It uses multi-sectoral models which understand cities as adaptive complex systems. The project displays three contextual scenarios in the 2050 horizon. The scenarios are intended to be used for policy-making and long-term planning by local stakeholders and organizations.

3.4. Sustain City (ETHZ, 2014). The ETH of Zurich has created a future cities research line with the intention of developing new analytical tools. This is a FP7-funded research project which aims to integrate modern mobility simulations with the latest micro-simulation land use models. Sophisticated simulation models deal with several time horizons and multi-scale spatial resolutions. Impact may be limited to academic circles.

4. Corporate Initiatives. In the last few years, big technology and consulting corporations have jumped eagerly into the Smart Cities market because they perceive big business opportunities. Smart Initiatives try to resolve future cities' key challenges. Three initiatives were assessed:

4.1. Logistics 2050 (Deutsche Post DHL, 2012). This study presents five different scenarios for the year 2050 and explores their implications for the logistics industry as well as for city systems. It focuses on external forces that affect urban complexity. Renowned academics and experts from a variety of fields were invited to provide insights for the scenarios through interviews and workshops. It has had ample dissemination.

4.2. Smart City Malaga (Endesa, 2014). Endesa, a Spanish utility company, led a consortium of several companies and research centers to increase energy efficiency and diminish $\mathrm{CO}_{2}$ emissions in Malaga by implementing new energy management systems. This initiative focused strictly on energy issues without taking into consideration other urban dimensions. No foresight exercise was undertaken. Impact has been highly visible on citizens. 
4.3. New Songdo City (KPF, 2003). Cisco Systems has been heavily involved in the design and development of a new town near Seoul, South Korea. New Songdo is supposed to become the paradigm of a future smart city as well as a thriving business center in South East Asia. In this initiative prevails a technological and economic oriented vision, ignoring other urban dimensions. No conventional foresight exercise has been carried out. Though progressing slowly, this initiative has gained wide international recognition.

4.4. IBM Smarter Planet (IBM, 2010). This is a generic initiative undertaken by IBM to develop a series of products geared to optimize the basic services of a city. Diverse functional dimensions of a city are analyzed and contextualized under a multi-system vision. No foresight exercise or stakeholders' involvement have been carried out during the development of this initiative. Its impact is very high because several projects worldwide have been implemented under this vision.

5. Architectural Initiatives. Architects and spatial planners have traditionally expressed on visual and narrative terms how cities should be designed for the coming generations. Two types of approaches can be differentiated: city projects which are meant to be built and utopian city visions which tend to explore new urban models. Four initiatives were assessed:

5.1. Masdar City (Foster + Partners, 2013). This is a new urban settlement to be built in Abu Dhabi, which uses extensively new technologies to create a city without cars, $\mathrm{CO}_{2}$ emissions and waste. Urban complexity is partially considered since technology is adapted to a specific local context. This is a good example of what architects understand by future visions. The city is under construction, but experiencing considerable delays. Significant impact at the international scene.

5.2. Dongtan Eco City (Arup, 2010). New town to be built near Shanghai. It was planned as an autonomous and sustainable city which would make an efficient use of energy and waste. This initiative slightly deals with urban complexity issues and it has not developed a proper foresight exercise. Presently, the plan has been abandoned.

5.3. Hydro-net SF2108 (Ivamoto, 2008). It is a utopian Project, winner of the context "History Channel's City of the Future". Its purpose was to design a self-sufficient and sustainable city in the 2108 horizon by creating a superimposed infrastructure that would allow gathering and distributing resources, thus avoiding urban sprawl. It is just a speculative exercise that understands urban complexity and makes use of foresight tools. Very limited impact.

5.4. 2050 Ultra Flood Plain (Shma, 2012). Its objective is to create a new urban development in Ayutthaya, Thailand, which will adequately integrate flood plains and man-made structures so as to avoid environmental impacts in the 2050 horizon. This initiative deals extensively with urban complexity and displays future visions without an explicit foresight methodology. Very limited impact.

Assessment of the five case studies groups has been compiled in a single table (see Table 1) so as to provide an overview of the results in order to detect commonalities and differences among the initiatives. Four levels of compliance with assessment criteria were considered: high, medium, low and non-compliance. 


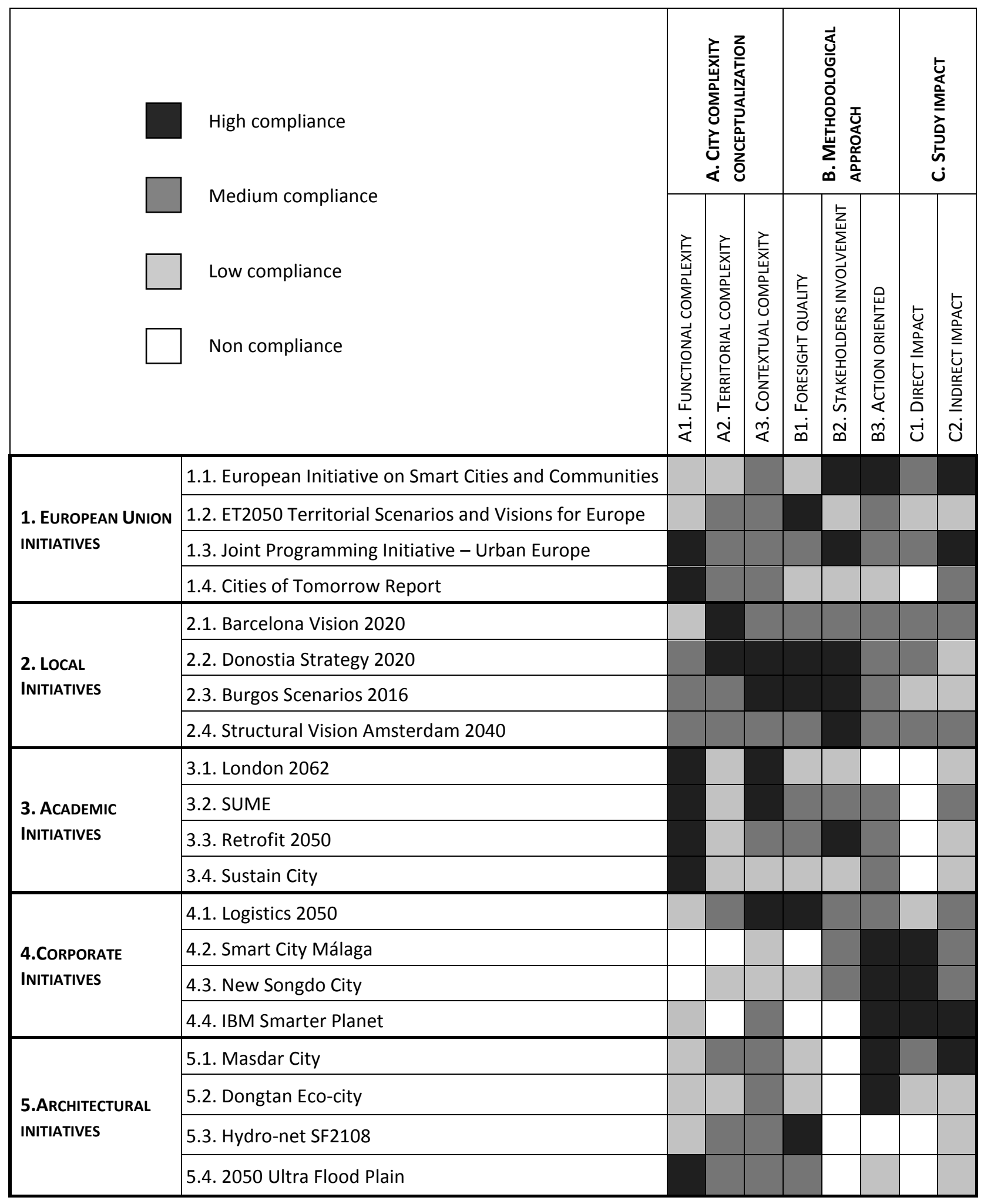

Table 1: Assessment of case studies Source: Authors elaboration 
The first group, focused on European initiatives, scores relatively high regarding consideration of city complexity and quality of foresight processes. Since this type of studies tend to guide and support policy making among member states, they do not present significant direct impacts. On the contrary, they tend to have a stronger indirect impact on urban societies.

The second group of initiatives shows high scores in understanding city complexity and in performing foresight exercises. It is worth noticing that they make a significant effort in getting involved local stakeholders along foresight exercises, as it could be expected in most planning processes promoted by municipalities. Impacts tend to be higher when a foresight exercise nurtures a strategic plan or a master plan.

The group of academic initiatives scores high in conceptualizing city complexity, while they show poorer results regarding methodology and impacts. The lack of well-established objectives and the tendency to discuss broad concepts and challenges may explain these results.

In opposition to the former group, corporate initiatives tend to pay less attention to city conceptualization, while they care more about using reliable methodologies and getting tangible impacts. This outcome seems to make sense since corporations focus in specific not broad issues and to establish very clear objectives for their studies. In other words, they are pragmatic initiatives which sacrifice conceptualization in favour of implementation.

The architectural initiatives group shows some significant differences. Architects show some interest in exploring city complexities, but they are not so prone to undertaking collaborative foresight exercises with local stakeholders. In fact, they display future city visions with strong utopian character. This may explain the difficulties to materialize their visions in built form, while they have a wide appeal on urban societies.

An overall view to the results shown in Table 1 renders a number of interpretations. First of all, most initiatives consider contextual complexity, while not all of them engage in a thoughtful reflection on functional and territorial complexity. Academic and European funded research initiatives offer a good understanding of city's complexity, while corporate initiatives tend to be weaker in this respect.

Secondly, foresight approaches tend to be methodologically sounder in European and local initiatives. In general terms, stakeholders' involvement could be improved in most groupings, but it is particularly poor in architectural initiatives.

Thirdly, corporate initiatives seem to achieve stronger impacts on the cities than academic and architectural initiatives. European studies tend to have greater indirect than direct impacts. In other words, strictly foresight oriented initiatives generate more indirect impacts, while pragmatic oriented initiatives show more direct impacts.

Finally, initiatives taken by public administrations show a better score balance than the rest of the groups because they combine analytical rigor with the search for practical objectives.

\section{Conclusions}

Though the present evaluation is limited and needed of further research, some findings may offer tentative answers to the three questions posed at the beginning of the paper.

Regarding urban complexity, few initiatives take it into serious consideration. The undeniable difficulty for understanding and displaying complex functional systems gives place to simple and sectoral approaches which inevitable provide biased urban visions. In brief, few projects are capable of producing an integrated future vision of the city. 
In respect to methodology, there seems to be a difference about how foresight practitioners and urban planners approach envisioning the city. Foresight specialists tend to ignore spatial challenges, while urban planners pay less attention to socioeconomic trends. Instead of exchanging expertise and becoming complementary, both positions remain isolated in their own "comfort zone", affecting the quality of urban visions. In other words, doubts arise about the appropriateness of the foresight tools employed by urban planners and about the understanding of foresight practitioners of the complex and dynamic nature of contemporary cities.

Finally, results are not conclusive about foresight studies being capable of influencing policy making. It seems clear that foresight studies by themselves do not usually have a direct impact on the city, unless they nurture a strategic plan or a city plan. Only some municipalities grasp the potential of foresight to formulate urban strategies.

Some other general conclusions can be drawn. Firstly, there are collaboration opportunities among different foresight initiatives. For example, academic initiatives achieve better scores on city conceptualization, while corporate initiatives outstand on methodology and study impacts; therefore, it may be worth mixing both approaches in collaborative projects so as to achieve more articulated city visions. As a matter of fact, many European Union projects require collaboration among public administrations, private business and universities.

Secondly, foresight studies in the urban realm should incorporate analytical methods capable of dealing with spatial issues. Just as well, physical planners should be more involved in exploring social, economic and technological impacts on the urban fabric. Organizing multidisciplinary teams would certainly help in this respect. New planning methodologies and communication technologies should support collaborative work and enlighten urban complexity.

Since research results are not conclusive, additional efforts could extend our findings. Progress should be made to characterize the city as a complex and dynamic system. Futures studies should be reinvented as a field of practical knowledge for planning professionals. Alternative ways should be explored by which stakeholders, citizens, and experts' networks could be involved more effectively in foresight exercises. New tools should be developed to assess (exante, in-itinere and ex-post) the impact of future studies on the city.

In sum, this work may provide some clues for developing new and more creative ways for envisioning futures in highly complex functional and multi-dimensional systems, as contemporary cities happen to be.

\section{References}

ARUP (2010). Dongtan Eco-City, Shanghai. http://www.arup.com/ assets/ download/8cfdee1a-cc3e-ea1a25fd80b2315b50fd.pdf (accessed on 20.03.2014)

Asociación PLAN EstratÉGICO de BuRgos (APEB) (2009). Estudio de prospectiva territorial para la ciudad de Burgos. (unpublished report). Burgos: APEB.

Associació Pla Estratègic Metropolità de Barcelona (APEMB) (2010). Barcelona Visión 2020: Una propuesta estratégica. Barcelona: PEMB.

Austrian Ministry of Science and Research et Al. (2010). Joint Programming Initiative Urban Europe. Global Challenges - Local Solutions. Paper delivered to the GPC, 16-03-2010.

BeLL, S. \& PASKINS J. (eds.) (2013). Imagining the Future City: London 2062. London: Ubiquity Press.

CALOF, J., MiLleR, R. \& JACKSON, M. (2012). "Towards impactful foresight: viewpoints from foresight consultants and academics", Foresight, 14 (1), pp.82-97.

DeUtSChe Post DHL (2012). Delivering tomorrow. Logistics 2050 A Scenario Study. Bonn: Deutsche Post AG. 
5th International Conference on Future-Oriented Technology Analysis (FTA) - Engage today to shape tomorrow Brussels, 27-28 November 2014

EAmes, M. ET AL. (2013). Retrofit City Futures: Visions for Urban Sustainability. www.retrofit2050.org.uk.

ENDESA (2014). Smartcity Málaga: Un modelo de gestión energética sostenible para las ciudades del futuro. Madrid: Dirección General de Distribución de Endesa.

EuRopean Commission (EC) (2012). Communication from the Commission on Smart Cities and Communities European Innovation Partnership. Brussels, C(2012) 4701 Final (10-07-2012).

EuRopean Commission (EC) (2011). Cities of Tomorrow: Challenges, visions, ways forward. Brussels: Directorate General for Regional Policy.

European Spatial Planning Observation Network (ESPON) (2013). ET 2050: Territorial Scenarios and Visions for Europe. Second Interim Report (30-04-2013). Luxembourg: ESPON.

Fernández GüELL, J. M. \& Redondo, L. (2012). “Linking territorial foresight and urban planning”, Foresight, 14 (4), pp. 316-335.

FERnÁNDEZ GüELL, J. M. (2011). "Recuperación de los estudios del futuro a través de la prospectiva territorial", Ciudad y Territorio - Estudios Territoriales, No. 167, pp. 11-32.

- (2006). Planificación estratégica de ciudades: Nuevos instrumentos y procesos. Barcelona: Editorial Reverté.

Foster + PARTners (2013). "Masdar City 2007-. Abu Dabi (EAU)", AV Monografías, 163-164, pp. 310-315. Arquitectura Viva S.L., Madrid, ES (sep.- dic. 2013)

IBM INSTITUTE FOR BUSINESS VALUE (2010). Ciudades más inteligentes para un desarrollo sostenible. Como optimizar los sistemas de la ciudad en una economía basada en el talento. New York: IBM Global Business Service.

ISSERMAN, A. M. (1985), "Dare to plan: An essay on the role of the future in planning practice and education", Town Planning Review, No. 56 (4), pp. 483-491.

IWAMOTO SCOTT ARCHITECTS (2008). Hydro-net SF2108. http://www.iwamotoscott.com/filter/SPECULATIONS/HYDRONET-SF2108 (accessed on 09.01.2014)

Johnston, R. (2012). "Developing the capacity to assess the impact of foresight", Foresight, 14 (1), pp.56-68.

Kohn Pedersen Fox Associates (KPF) (2003). New Songdo City. Urban design principles book. Songdo IBD. http://www.songdo.com/songdo-international-business-district/why-songdo/a-brand-new-city/kpf-urbandesign-principles.aspx (accessed on 09.04.2014).

Kubeczko, K., RavetZ, J., Giessen, A. \& Weber, M. (2011). Screening urban foresights and studies supporting forward looking activities. Input to the EFP Policy Workshop on "Screening Urban Foresight", Brussels 28-04-2011.

LauWers, Conny; Ponteyn, Barbara \& Zanen, Koos van (2011): "Structural Vision Amsterdam 2040", Plan Amsterdam Magazine. No 01/2011. Amsterdam: Department of Physical Planning (DRO).

Plan Estratégico Donostia-San Sebastián (PEDSS) (2011). Estrategia 2020 Donostia-San Sebastián. Donostia: PEDSS. http://donostiafutura.com/estrategia2020/pdf/E2020DSS es.pdf (acceso: 30.12.2013)

SCC-EIP (2013). Strategic Implementation Plan. European Innovation Partnership on Smart Cities and Communities (14-10-2013).

Schremmer, C. et AL. (2011). Urban Development Scenarios (Parts A, B \& C). SUME Working Papers. Vienna, March 2011.

SHMA (2012). 2050 Ultra Flood Plain. http://worldlandscapearchitect.com/2050-ultra-flood-plain-ayutthaya-thailandshma/\#.UxzzzPmwbO8 (accessed on 06.11.2013)

Swiss Federal INSTITUte of TeChnology ZURICH (ETHZ) (2014). Sustain City. www.sustaincity.org accessed (24-092014).

WaCHS, M. (2001), "Forecasting versus Envisioning: A new window on the future", American Planning Association Journal, Vol. 67 No. 4, pp. 367-372.

THEME 3: CUTTING EDGE FTA APPROACHES 